\title{
20 INCIDENCE AND MECHANISM OF ACUTE INJURIES IN IRAN KARATE CHAMPIONSHIP 2010
}

Gholam Ali Ghasemi, Seied Mohammad Marandi, Mohammad Batavani, Mohammad Reza Batavani Faculty of Physical Education and Sports Sciences, University of Isfahan, Isfahan, Iran

\subsection{6/bjsm.2010.078725.20}

There is a growing need for research in competitive activity of karateists. The aim of this study was to investigate the incidence, type and mechanism of injuries in Iranian professional men karate players. Seven hundred and sixty-seven men karate players (means $\pm \mathrm{SD}$; age, $21.7 \pm 3.2$ years, weight, $69.4 \pm 8.9$, height, $176.9 \pm 6.4 \mathrm{~cm}$ ) who participated in Iran men karate championships in 2010, took part in this study. An injury form was used to collect data. The form consisted of two sections: personal data (age, sex, height, weight, etc) and injury data. 
Variables such as incidence, location, causes and mechanisms of injury were considered and recorded after competitions. $\chi^{2}$ Test was used to analyse data. The results of this study showed that in the total of 739 matches (kata and kumite), 289 injuries occurred. Competitors have more injuries in the upper body than in the lower body (229 vs 60), ( $\lambda^{2}=21.24$, $\mathrm{p}<0.05)$. Incident rate of injuries was 15.4 injuries per $100 \mathrm{~min}$ of match (0.39 injuries per each match) and 376.7 injuries per
1000 athletes. Skeletal injury (44.2\%) was the most common injury, face $(32.6 \%)$ was the most common injured area, contusion $(59.5 \%)$ was the main injury, opponent technical mistake $(71 \%)$ was the main cause of injuries and opponent's attack $(54.6 \%)$ was the main mechanism of occurrence of injuries. So, decreased mistake kick, protective pads and the safe use of equipments and rules modification are the best ways of minimising the injuries in karate players. 